\title{
Climate and Tourism: Generational Differences and Effects on
}

\section{Satisfaction}

\author{
Nancy Hritz, Alexia Franzidis, James Herstine, Doug Gamble \\ University of North Carolina, Wilmington, USA
}

\begin{abstract}
Climate, weather, and its attributes such as temperature and number of rainy days are essential for the success of many tourism destinations. As climate scientists have determined that climate changes are inevitable, tourism destinations need to determine how to best manage these changes and mitigate any negative consequences. In addition, the perceived weather and/or climate at a destination can have as much weight on an individual's travel experience as the actual weather. The purpose of this study was to examine climate attributes and their importance on a traveler's behavior and satisfaction. Two hundred and sixty four surveys were gathered in the Mediterranean regions of Europe in the summer of 2009. Regression analysis revealed that climate attributes play a role in a traveler's satisfaction with their choice of a destination, but the traveler does not feel that climate changes are affecting their destinations as a whole. Analysis of variance (ANOVA) determined generational age differences in importance of climate attributes and if climate changes are affecting destinations. Management considerations for destination planners are explored.
\end{abstract}

Keywords: climate change, climate attributes, traveler’s behavior, satisfaction, generational age groups

\section{Introduction}

The words "climate change” and "global warming” spark passion and debate among governments, citizens, and business owners. This leads to much discussion on rising sea levels, greenhouse emissions, and depletion of rain forests along with many other related topics. It is considered such a hot issue that much research on climate change has been undertaken, examining specifically its effects on the environment, the economy, and an individual's quality of life. Much of this research has followed the process established by the United Nations Framework Convention on Climate Change (UNFCCC) and the Kyoto Protocol (Dubois \& Ceron, 2006).

The tourism industry, if taken as the equivalent of a country by the amount of pollution it produces, has the fifth largest emissions after USA, China, Russia, and India. Much of these emissions are contributed by the transportation sectors of aviation and automobiles, with $40 \%$ and $32 \%$ respectively, and accommodations adding an additional 21\% (Strasdas, 2010). This information implies the industry's substantial contribution towards climate change, yet despite this fact, the tourism industry has received little attention by the UNFCCC.

Nancy Hritz, Ph.D., associate professor, Recreation, Sport Leadership, and Tourism Management, University of North Carolina. Email: hritzn@uncw.edu.

Alexia Franzidis, Ph.D., assistant professor, Recreation, Sport Leadership, and Tourism Management, University of North Carolina.

James Herstine, Ph.D., professor, Recreation, Sport Leadership, and Tourism Management, University of North Carolina.

Doug Gamble, Ph.D., professor, Department of Geography and Geology, University of North Carolina. 
While tourism is not currently a target for the causes of climate change, researchers do recognize the effect that the industry is having on destinations. Since 2000, there has been an explosion of studies focused namely on transportation, contributing to climate change and seasonal destinations such as ski resorts. For example, due to millions of individuals who travel annually, there is a substantial impact on the environment in terms of land use and energy consumption (Gossling, 2002). In turn, these changes have altered specific natural resources like oceans, lakes, mountains, and various types of flora or fauna (Nickerson, Becerra, \& Zumstein, 2011). Ironically, many of the features climate change alters are some of the key attractions that motivate tourists to visit certain destinations. Changes to these items could result in changes in tourist demand and the flow of tourists among destinations.

One such climate feature is temperature and precipitation (Lise \& Tol, 2002). This attractor has been recognized as a motivator for tourists, particularly those seeking sun during their winter months (Rosselló-Nadal, Riera-Font, \& Cárdenas, 2011). Significant changes in temperature may lead to unfavorable or uncomfortable conditions, therefore resulting in tourists choosing alternative vacation destinations, shifting their vacations to different times of the year, or impacting their levels of satisfaction whilst on vacation.

Within academia, while the relationship between tourism and climate was noticed in the 1950s, climate was viewed as something stable for destinations (Hein, Metzger, \& Moreno, 2009). However, climate scientists have determined that climate change is inevitable. Due to the competitive nature of tourism businesses and the sensitivity of destination choices by tourists, the question for tourism professionals is how to best manage these changes and mitigate any negative consequences (Lise \& Tol, 2002). At present, scant research has addressed tourist satisfaction directly with climate conditions, and few assessments exist to assist managers in addressing climate change proactively (Moreno \& Becken, 2009). Therefore, the purpose of this study was to examine climate attributes and their importance on a traveler's behavior and satisfaction. It is hoped that findings will assist in identifying the kinds of information that may be useful in maintaining successful tourism enterprises.

\section{Review of Literature}

Tourism is similar to other industries in that the economic stability of such is climate sensitive. For example, the agricultural industry and its success are climate dependent. Most research suggests that climate influences the destination choice of tourists (Bigano, Hamilton, \& Tol, 2006; Gossling \& Hall, 2006; Lise \& Tol, 2002; Maddison, 2001), and many people travel to specific destinations with the expectation of more favorable climactic conditions than where they live (Amelung, Nicholls, \& Viner, 2007). For example, Perry (1993) found that $70 \%-80 \%$ of holiday makers from the United Kingdom ranked climate as a primary motivator for their travels and Lohmann and Kaim (1999) found that Germans ranked climate as their third primary motivator.

This type of behavior can be seen throughout tourism's history with British seaside resort and beach holidays playing a central role in the development of coastal towns such as Brighton and Bradford (Walton, 2005). Similarly, the first mass tourism " 4 S" vacation package of Sun, Surf, Sand, and Sex was based around people seeking sunnier pastures during their vacations. Nowadays, this type of behavior still exists and certain nationalities are infamous for frequenting particular destinations, the most famous being British citizens' traveling to the Mediterranean coast to escape their dark and cold winter (Perry, 2000). 


\section{Climate Preferences}

The perceived weather and/or climate at a destination can have as much weight on travel decisions as the actual weather or climate, or impact a tourist's level of enjoyment when on vacation (Curtis, Arrigo, Long, \& Covington, 2008). For example, De Freitas's (1990) study in Kure Beach Australia found that weather, including air temperature, wind, and clouds, was considered crucial for beach visitation. As many recreational activities and attractions depend on the weather, subtle changes in such may impact the level of comfort, involvement, or safety of tourists, thus impacting the number of visitors to particular areas (Moreno \& Becken, 2009).

Numerous studies have examined tourist preferences for specific climate and weather attributes. The Tourism Climate Index (TCI), developed by Mieczkowski (1985), was the first model designed to assess the general comfort level for tourism activities based on climate attributes. The original TCI has five sections: (1) daytime comfort (maximum daily temperature, minimum daily relative humidity); (2) daily comfort (mean daily temperature, mean humidity); (3) precipitation (total precipitation); (4) sunshine (total hours of sunshine); and (5) wind (average wind speed).

Several studies have used a modified TCI for a number of destinations, across the globe including beach areas and major cities to assess how seasonality might be affected by climate conditions (Amelung et al., 2007; Matzarakis \& De Freitas, 2001; Morgan, Gatell, Junyent, Micallef, Özhan, \& Williams, 2000). Hamilton and Lau (2004) used the TCI to examine the role information about a destination's climate has in the decision-making process of tourists in selecting a destination. The authors of the study found several climate characteristics that were important for the traveler. First, outside temperature was found to be a dominant factor as well as the number of rainy days, duration of sunshine, and water temperature. In addition, Hamilton and Lau (2004) concluded that weather and climate, although having two very different literal meanings, are considered synonymous by the general public and therefore viewed as the same thing. Thus, Hein et al. (2009) called for further specification to assist with clarification.

The TCI may not be synonymous for all activities. Hein et al. (2009) commented that the majority of studies focus on the optimal temperatures for light activities, with the result being $20^{\circ} \mathrm{C}-27^{\circ} \mathrm{C}$; however, Scott, Gossling, and De Freitas (2008) found that the range of $26^{\circ} \mathrm{C}-28^{\circ} \mathrm{C}$ was the ideal range for beach activities. Similarly, studies have shown that tourists from different nationalities have a variety in their preferences. Lise and Tol (2002) found that OECD tourists preferred an average of $21^{\circ} \mathrm{C}$ as the hottest temperature, whereas Maddison (2001) found that British tourists' optimal average daytime maximum is $29^{\circ} \mathrm{C}$.

\section{Shifts in Destination Temperatures}

As warming continues to occur, it is predicted that tourists will spend their vacations in alternative destinations (Rosselló-Nadal et al., 2011). Higher temperatures will negatively change the optimal holiday weather conditions, thereby affecting the outbound flow of tourists (Rosselló-Nadal et al., 2011). As observed by Carter (1991), a shift in climate of $4^{\circ} \mathrm{C}$, regardless of the level of precipitation, would alter the optimal summertime climate. Due to this weather sensitivity of outbound tourists, this redistribution poses a serious threat to destinations that are heavily reliant upon income from tourism (Bigano et al., 2006). For example, in Europe, temperature, the number of sunlight hours, and the lack of precipitation dictate a large amount of international tourism flow and changes to this may impact tourism receipts (Amelung \& Viner, 2006). 
However, because the predicted impacts and adaptations will be country specific, changes in tourism flow will be to the advantage and disadvantage of individual destinations (Gossling \& Hall, 2006; Hein et al., 2009). It is predicted that tourist expenditure in colder countries may double, and tourism expenditure in warmer countries may halve (Bigano et al., 2006).

There have been several studies conducted to predict anticipated warming scenarios. For example, using historical weather data from 1961 to 1990, Amelung et al. (2007) constructed a series of current and future weather time spans, and compared the results with conditions within the TCI. Based on their calculations, they found that countries within the Mediterranean regions of Spain, France, Italy, Greece, and Turkey may experience a decline in tourism numbers, as their destination is likely to become too hot for comfort in the peak of summer. They also noted that similar types of destinations, such as the Caribbean, may also suffer from similar situations. However, they found that countries within the Northern Europe will receive an improved number of visitors.

Bigano et al. (2006) also examined how travelers' decisions on a destination may be shaped in the future by climate changes. They found that individuals who live in a warmer climate may already be more selective than those who live in a colder climate. In other words, travelers who live in a colder climate did not seem to mind extreme hot or colder temperatures when they traveled. Those who live in a warmer climate were more likely to prefer a destination that was more moderate in temperature. Bigano et al. (2006) concluded that destination and accommodation providers in an area in which temperatures are likely to rise should concentrate on the individuals from a colder climate, as they are more likely to receive strengthened loyalty from travelers from cold places rather than hot places.

Braun, Lohmann, Maksimovic, Meyer, Merkovic, Messerschmidt, Riedel, and Turner (1999) conducted hypothetical experiments to test if tourists would still choose or prefer a destination if the climate changed from their present conditions. Their results, restricted to tourists in a Northern Germany coastal region, indicated that tourists would be less inclined to visit if conditions changed. Perry (2000) also commented that some tourists were reluctant to visit destinations that are predicted to be warmer as they pose an increased risk to an individual's health, with regard to skin cancer, or suffering from symptoms induced by heat waves.

Hein et al. (2009) reported two scenarios for Spain based on the anticipated changes in climate. The first showed an average decrease of tourists by $14 \%$, with a $26 \%$ decline in the summer and a $6 \%$ decrease for the rest of the year. The second scenario predicted that tourist numbers would drop $18 \%$ in the summer months (June-August), however, the remainder of the year would experience an increase of $4 \%$ in visitor nights. The main difference for each scenario is the number of arising competing destinations due to changes in their weather conditions (now having better weather conditions), or modifications in their home countries' weather (as Spain receives a large number of German and British tourists and both are predicted to get warmer).

\section{Shifts in Seasonality}

Therefore, certain destinations that are predicted to be affected by changes in climate will experience shifts in seasonality, whereby optimal temperatures will fall outside of the conventional "summer holiday" period (Rosselló-Nadal et al., 2011). This change could shift seasonality and see an improvement in tourism numbers in the shoulder seasons of autumn and spring and a decrease in summer (Amelung \& Viner, 2006). 
Amelung et al. (2007) noted that these changes in temperature may alleviate the current pressures caused by seasonality. At present, periods of high seasonality typically revolve around the timing of religious and school holidays, as well as standing societal practices or norms (Amelung et al., 2007). These periods are viewed as the "window of opportunity" to plan holiday activities, and this tradition is still prevalent despite any changes to modern day lifestyles of families.

While the extension of the shoulder seasons is good, the problem arises when considering the formal breaks structured around the summer months, and how this will constrain tourists from traveling to their traditional locations, thus forcing them to choose an alternative destination if they are interested in seeking optimum temperatures. Amelung et al. (2007) also noted that due to travel parties having a variety of travel times (e.g., different dates of staggered school holidays), there may be a mismatch of available holiday time resulting in changes in destination choices. If this problem arises, then previously chosen locations may receive little to no visitation in their shoulder seasons, as tourists choose alternative destinations for their summer vacations (Rosselló-Nadal et al., 2011).

Hein et al. (2009) noted that this may not be a problem for the older generation who has a greater flexibility in the timing of their vacations. Similarly, Amelung and Viner (2006) believed that because there has been a shift in couples without young children and an increase in pensioners, both of whom have greater flexibility, it lessens the potentially detrimental impacts that changes to seasons may have on tourism destinations. Hamilton and Lau (2004) urged for further investigation to pursue differences among tourist groups in terms of demographics or purpose of travel. Rosselló-Nadal et al. (2011) agreed, describing how much of the research to date has focused around nationalities or activities rather than their age or generation. Furthermore, the nationality clustered studies have focused primarily on residents from one country, or just a few countries, and few have attempted to encompass all destinations or destinations in general (Bigano et al., 2006).

\section{Differences in Generational Age Groups}

The practice of examining individuals by their generation is the idea that individuals are fundamentally shaped and their behavior is influenced by significant events during their generation. Used extensively by marketers, generational marketing has been successful in predicting consumer behavior by age and could be a useful tool to assess climate preferences.

The Silent Generation came of age in the 1950s and is considered as a generation of helpers who desire to make the world a safer place after times of war. This generation was one of the first to redefine the concept of age. They view themselves as active individuals who feel 15 years younger than they really are (Frenkel, 2008). Baby Boomers are defined as busy individuals who look for convenience and they are among the first to truly believe that the world will improve with time. A large group in terms of actual numbers, they are either retiring or nearing retirement age (Fishman, 2011). This group also looks to extend their healthy years by being physically active in their travel and engaging in activities such as yoga and other spiritual activities (Yeoman, 2012).

Generation X (Gen X) is most likely to be more highly educated than the generations before them and more entrepreneurial in business (Fishman, 2011; United States Census Bureau, 2009). They are more likely to engage in volunteer activities in their travel and also desire to engage in multiple leisure activities when they travel. Generation Y (Gen Y), also known as Millennials, came of age in the era of the internet. In their travel, they are motivated to do so more often and view travel both domestic and international as a mainstream way of life (Pendergast, 2010; Richards, 2007). 
Age has shown to be an important factor in a person's attitudes towards the environment in general. McMillan, Hoban, Clifford, and Brant (1997) found that younger individuals believed in protecting the environment more than older individuals. This finding lends to the notion that as people age, they have more conservative views (D. A. Vlosky \& R. P. Vlosky, 1999). More recent studies have investigated relationships with age and climate change. A recent study completed in the countries of the European Union found that persons aged 55 or older were less likely to state that climate change is a serious problem. In addition, middle aged and younger ages equated the state of the economy as equally important as climate change (Eurobarometer, 2009).

This study aimed to expand upon the current scholarly activity asked the following research questions: (1) What climate variables are important in the choice of a destination for tourists? (2) What effects do these have on perceived effects of climate change on a destination and overall satisfaction with climate at the destination? and (3) Are there any differences among generational age groups, their satisfaction, perceived effects, and climate attributes?

\section{Methods}

The participants for this study were a convenience sample of adult English-speaking travelers traveling in the Mediterranean regions of Italy, Greece, Turkey, and France during the summer of 2009, specifically from mid June to mid July. The subjects were approached by undergraduate students participating in a summer study abroad experience in public areas such as airports, organized tours, and on a cruise ship. In some cases, the survey was read aloud to some survey participants as English was not their first language. A total of 264 surveys were obtained with this process.

The paper and pencil survey was divided into three separate sections. The first section asked participants demographic questions such as country of origin, age, education, and gender. It also included questions about travel party size, daily travel budget, and how they planned their travel. Section 2 asked each participant to rate destination climate attributes such as outside water temperature, duration of sunshine, number of rainy days, UV radiation, and air quality. The participants were asked to rate the importance of each climate attribute on a 5-point Likert scale ranging from $1=$ Not at all important to $5=$ Very important. These were modified TCI climate attributes borrowed from Hamilton and Lau (2004). Section 3 determined the extent of the participant's knowledge or attitude to climate conditions and their association with their destination choice. Questions addressed satisfaction with climate conditions at their chosen destination and if they felt that climate changes were affecting travel destinations as a whole.

These were also measured on a 5-point Likert scale ranging from $1=$ Not at all to $5=$ Very much.

Additional questions in this section asked how often the participants checked the weather before their trip and what sources they sought this information from. These were also borrowed and modified from Hamilton and Lau's (2004) study.

Several analyses were used to interpret the data using Statistical Package for Social Sciences (SPSS) 18.0. First, descriptive statistics were computed for an accurate profile of the sample. The individual age groups of the participants were grouped together into generational segments for further analysis. These were the Silent Generation (age of birth during 1925-1942), Baby Boomers (age of birth during 1943-1960), Generation X (age of birth during 1961-1981), and Generation Y (age of birth during 1982-2000). These age groups were formed based upon the extensive generational marketing research by Fishman (2011). 
Next, a standard multiple regression allowed for an examination of which demographic variables and climate conditions were significant predictors of an individual's perception of climate's effects on travel destinations or their satisfaction of climate conditions at their destination. Finally, a series of analysis of variance (ANOVA) tests were used to examine differences among the age groups of Silent Generation, Baby Boomers, Generation X, and Generation Y in their perceptions of climate-related conditions and travel destinations.

\section{Results}

A complete demographic profile of the participants can be found in Table 1. Descriptively, each gender was represented equally with $49.8 \%$ males and $50.2 \%$ females. A majority of their ages fell into Generation Y (38.5\%), however, all the other age groups, Silent Generation, Baby Boomers, and Generation X, were well represented. They were an educated group, with $65.4 \%$ of the sample reporting at least completing some college or having finished a college degree.

According to Table 1, a majority of the participants traveled with at least one other person (39.6\%), however, most of the participants traveled in a larger group of three or more (45.8\%). Daily budget for their travel was modest, with $81.4 \%$ reported having $\$ 150.00$ or less budgeted. Overwhelmingly, the participants planned their travel independently (61.1\%) without using a travel agent or group tour operator. Interestingly, however, their sources of information for planning the travel were not all internet-based. Many relied on family and friends (13.6\%), own past experience (27.3\%), or a travel agent (25.4\%) instead of internet reviews (14.0\%).

Table 1

Descriptive Profile of the Participants

\begin{tabular}{|c|c|c|}
\hline Variable & No. & $\%$ \\
\hline \multicolumn{3}{|l|}{ Gender } \\
\hline Male & 127 & 49.8 \\
\hline Female & 128 & 50.2 \\
\hline \multicolumn{3}{|l|}{ Age } \\
\hline Silent Generation (1925-1942) & 23 & 8.7 \\
\hline Baby Boomers (1943-1960) & 64 & 24.3 \\
\hline Generation X (1961-1981) & 75 & 28.5 \\
\hline Generation Y (1982-2000) & 101 & 38.5 \\
\hline \multicolumn{3}{|l|}{ Country of residence } \\
\hline United States & 70 & 28.8 \\
\hline United Kingdom & 68 & 28.1 \\
\hline Italy & 18 & 7.4 \\
\hline France & 20 & 8.2 \\
\hline Germany & 13 & 5.4 \\
\hline Holland & 3 & 1.2 \\
\hline Switzerland & 3 & 1.2 \\
\hline Spain & 9 & 3.7 \\
\hline Greece & 1 & 0.4 \\
\hline Scotland & 7 & 2.9 \\
\hline Sweden & 4 & 1.7 \\
\hline Australia & 9 & 3.7 \\
\hline Canada & 11 & 4.5 \\
\hline South America & 3 & 1.2 \\
\hline
\end{tabular}


(Table 1 continued)

\begin{tabular}{|c|c|c|}
\hline Variable & No. & $\%$ \\
\hline \multicolumn{3}{|l|}{ Country of residence } \\
\hline Russia & 2 & 0.8 \\
\hline Japan & 1 & 0.4 \\
\hline India & 1 & 0.4 \\
\hline \multicolumn{3}{|l|}{ Education } \\
\hline High school/GED & 34 & 13.1 \\
\hline Some college & 59 & 22.7 \\
\hline Completed a college degree & 111 & 42.7 \\
\hline Masters & 36 & 13.8 \\
\hline Doctorate & 8 & 3.1 \\
\hline Other & 12 & 4.6 \\
\hline \multicolumn{3}{|l|}{ Travel party size } \\
\hline Alone & 38 & 14.6 \\
\hline Two & 103 & 39.6 \\
\hline Three & 31 & 11.9 \\
\hline Four & 44 & 17.0 \\
\hline Five & 13 & 5.0 \\
\hline Six or more & 31 & 11.9 \\
\hline \multicolumn{3}{|l|}{ Daily travel budget (Euros) } \\
\hline$\$ 50.00$ or less & 52 & 21.4 \\
\hline$\$ 51.00$ to $\$ 75.00$ & 42 & 17.3 \\
\hline$\$ 76.00$ to $\$ 100.00$ & 36 & 14.7 \\
\hline$\$ 101.00$ to $\$ 150.00$ & 68 & 28.0 \\
\hline$\$ 151.00$ to $\$ 200.00$ & 7 & 2.9 \\
\hline$\$ 201.00$ to $\$ 250.00$ & 7 & 2.9 \\
\hline$\$ 251.00$ or more & 31 & 12.8 \\
\hline \multicolumn{3}{|l|}{ How to plan travel? } \\
\hline Independently (using the internet as an example) & 161 & 61.1 \\
\hline Travel agent & 64 & 24.2 \\
\hline Packaged tour with group & 36 & 13.6 \\
\hline Other & 3 & 1.1 \\
\hline \multicolumn{3}{|l|}{ Source of information for travel } \\
\hline Family/friends & 36 & 13.6 \\
\hline Own past experience & 72 & 27.3 \\
\hline Travel agent & 67 & 25.4 \\
\hline Internet reviews & 37 & 14.0 \\
\hline Other & 52 & 19.7 \\
\hline
\end{tabular}

The survey participant's overall perceptions of climate conditions and the perceptions of their effects on travel destinations are depicted in Tables 2 and 3. As a group, the participants appeared to be lukewarm on the idea that climate conditions were important when making a choice of travel destination. While they agreed that they were somewhat important, on average, they did not feel that climate conditions were extremely important. Of the 11 items presented to the participants, the climate conditions rated the highest of importance were number of rainy days $(M=3.83)$, maximum outside temperature $(M=3.67)$, water temperature $(M=3.66)$, and consistency of outside temperature $(\mathrm{M}=3.66)$. The climate conditions that were rated as least important were wind conditions $(M=3.04)$, air quality $(M=3.12)$, and $U V$ radiation $(M=3.18)$. 
Similar to the participants' perceptions of climate conditions, their impression of climate change affecting travel destinations as a whole was mild $(\mathrm{M}=3.52)$ as well as their satisfaction with climate conditions once they traveled to their destinations $(\mathrm{M}=3.45)$.

Table 2

Perceptions of the Importance of Climate Conditions and Destination Choices

\begin{tabular}{lll}
\hline Climate attribute & $\mathrm{M}$ & S.D. \\
\hline Maximum outside temperature & 3.67 & 0.962 \\
Water temperature & 3.66 & 1.192 \\
Duration of sunshine & 3.47 & 1.097 \\
Number of rainy days & 3.83 & 1.054 \\
Consistency of outside temperature & 3.66 & 1.126 \\
Amount of daily precipitation & 3.58 & 1.121 \\
Humidity & 3.54 & 1.066 \\
Cloudiness & 3.46 & 1.133 \\
UV radiation & 3.18 & 1.041 \\
Wind conditions & 3.04 & 1.112 \\
Air quality & 3.12 & 1.108 \\
\hline Climate awareness & & 1.193 \\
$\quad$ Feel that climate change is affecting travel destinations & 3.52 & 1.206 \\
\hline Satisfied with climate conditions once arrived at the destination & 3.45 & \\
\hline
\end{tabular}

Notes. Climate attributes are based on a 5-point Likert scale ranging from 1 = Not at all important to 5 = Very important; climate awareness is also based on a 5-point Likert scale ranging from 1 = Not at all to 5 = Very much.

Table 3

Multiple Regression Analysis of Perception of Climate Change Affecting Travel Destinations

\begin{tabular}{|c|c|c|c|c|c|c|}
\hline Variable & $N$ & $F$ ratio & $R^{2}$ & $\mathrm{~B}$ & $\beta$ & $t$-value \\
\hline The model & 264 & 1.134 & 0.385 & & & \\
\hline Constant & & & & 2.494 & & 1.351 \\
\hline Gender & & & & 0.202 & 0.085 & 0.709 \\
\hline Generation & & & & -0.245 & -0.188 & -1.500 \\
\hline Country of residence & & & & 0.070 & 0.077 & 0.685 \\
\hline Education & & & & -0.082 & -0.073 & -0.594 \\
\hline Travel party size & & & & -0.014 & -0.117 & -1.017 \\
\hline Daily budget & & & & 0.000 & 0.123 & 1.120 \\
\hline Maximum outside temperature & & & & 0.160 & 0.130 & 0.886 \\
\hline Water temperature & & & & -0.027 & -0.028 & -0.208 \\
\hline Duration of sunshine & & & & -0.070 & -0.061 & -0.397 \\
\hline Number of rainy days & & & & 0.158 & 0.161 & 0.863 \\
\hline Consistency of outside temperature & & & & -0.046 & -0.040 & -0.296 \\
\hline Amount of daily precipitation & & & & 0.025 & 0.024 & 0.186 \\
\hline Humidity & & & & -0.013 & -0.011 & -0.064 \\
\hline Cloudiness & & & & -0.356 & -0.373 & $-2.162^{* *}$ \\
\hline UV radiation & & & & 0.257 & 0.228 & 1.686 \\
\hline Wind conditions & & & & -0.073 & -0.077 & -0.523 \\
\hline Air quality & & & & 0.393 & 0.363 & $2.632^{*}$ \\
\hline
\end{tabular}

Notes. ${ }^{*}: p<0.01 ;{ }^{* *}: p<0.05$. 
Next, a regression analysis was conducted to determine what variables might predict an individual's perceptions of climate conditions at travel destinations. Entered into the first regression formula were all 11 climate condition survey items, as well as gender, age (grouped by generation), country of residence, education, travel party size, and daily budget as independent variables. The dependent variable was their perception that climate conditions are affecting travel destinations. This model was not significant $(F=1.134, p=0.127)$ and is illustrated in Table 3.

A second regression model was performed using the same independent variables as above. However, the independent variable for this model was satisfaction with climate conditions, while the participants were at a specific travel destination. This model was significant $(F=3.302, p<0.0001)$ and the results can be found in Table 4 . While none of the demographic variables contributed significantly, the climate conditions did. The significant predictors were water temperature $(p=0.046)$, number of rainy days $(p=0.006)$, cloudiness $(p=0.020)$, wind conditions $(p=0.001)$, and air quality $(p<0.0001)$.

Table 4

Multiple Regression Analysis of Perception of Satisfaction of Climate Conditions at Travel Destinations

\begin{tabular}{|c|c|c|c|c|c|c|}
\hline Variable & $N$ & $F$ ratio & $R^{2}$ & $\mathrm{~B}$ & $\beta$ & $t$-value \\
\hline The model & 264 & 3.302 & 0.661 & & & \\
\hline Constant & & & & 3.147 & & $4.265^{*}$ \\
\hline Gender & & & & -0.102 & -0.060 & -0.580 \\
\hline Generation & & & & -0.174 & -0.187 & -1.721 \\
\hline Country of residence & & & & 0.046 & 0.071 & 0.729 \\
\hline Education & & & & 0.092 & 0.114 & 1.076 \\
\hline Travel party size & & & & 0.002 & 0.020 & 0.204 \\
\hline Daily budget & & & & 0.000 & 0.108 & 1.140 \\
\hline Maximum outside temperature & & & & 0.004 & 0.004 & 0.034 \\
\hline Water temperature & & & & 0.163 & 0.235 & $2.034^{* *}$ \\
\hline Duration of sunshine & & & & -0.168 & -0.206 & -1.542 \\
\hline Number of rainy days & & & & 0.321 & 0.457 & $2.836^{*}$ \\
\hline Consistency of outside temperature & & & & 0.086 & 0.105 & 0.891 \\
\hline Amount of daily precipitation & & & & 0.041 & 0.057 & 0.509 \\
\hline Humidity & & & & -0.199 & -0.238 & -1.634 \\
\hline Cloudiness & & & & -0.241 & -0.355 & $-2.376^{* *}$ \\
\hline UV radiation & & & & -0.024 & -0.030 & -0.257 \\
\hline Wind conditions & & & & -0.296 & -0.443 & $-3.453^{*}$ \\
\hline Air quality & & & & 0.464 & 0.600 & $5.032^{*}$ \\
\hline
\end{tabular}

Notes. ${ }^{*}: p<0.01 ;{ }^{* *}: p<0.05$

Water temperature, number of rainy days, and air quality were positive relationships. Therefore, the warmer the water, the better the air quality and the more rainy days led to greater satisfaction at their destinations. Cloudiness and wind conditions were negative relationships. In other words, the less cloudy and the less amount of wind, the greater the satisfaction. The only curious result is the negative relationship with the number of rainy days. The sample here preferred more rainy days at their destinations. A closer look at the actual weather conditions in the Mediterranean sections of Italy, Turkey, Greece, and France in the summer of 2009 revealed higher temperatures above the averages for that time of year with averages of $28^{\circ} \mathrm{C}-29^{\circ} \mathrm{C}$ and actual temperatures of $32^{\circ} \mathrm{C}-33^{\circ} \mathrm{C}$. In addition, there was little to no precipitation, high humidity, and low wind 
speed (WUnderground, 2014). The results in the regression model may be a result of actual conditions in the area and a desire for a break from the heat at the height of summer.

Lastly, a series of ANOVAs among the age groups of the Silent Generation, Baby Boomers, Generation X, and Generation $\mathrm{Y}$ with their responses to perceptions of climate change at travel destinations revealed significant differences among the groups. Differences were found among the climate conditions of water temperature, duration of sunshine, number of rainy days, and amount of daily precipitation. The age groups also differed in their perceptions on climate change affecting travel destinations as a whole. These findings are illustrated in Table 5.

Post-hoc Tukey honestly significant difference (HSD) tests were performed and the individual means were examined to reveal where the differences exist for each item as a result of the ANOVAs. For water temperature, the Baby Boomers $(M=4.03)$ were significantly different from the Silent Generation $(M=3.09)$ and Generation Y $(\mathrm{M}=3.54)$ in its importance. Baby Boomers felt that water temperature is important to the travel destination choices more so than the Silent Generation or Generation Y.

Generation $Y(M=3.66)$ significantly differed from the Silent Generation $(M=3.05)$ and the Baby Boomers $(M=3.27)$ in the duration of sunshine for their travel. Therefore, Generation $Y$ felt more than the other two age groups that the length of the sunshine for the day is important in choosing a travel destination.

Number of rainy days also significantly differed in the post-hoc tests among the Silent Generation $(M=3.26)$, the Baby Boomers $(M=3.92)$, and Generation $X(M=3.95)$. Therefore, Baby Boomers and Generation $Y$ feel that the number of rainy days is more important than the Silent Generation in their choice of a destination.

Closely connected to the number of rainy days was the amount of daily precipitation. For this climate condition, the Baby Boomers age group $(M=4.05)$ significantly differed from all the other age groups: Silent Generation ( $M=3.39)$, Generation $X(M=3.46)$, and Generation $Y(M=3.41)$.

Table 5

ANOVA for Comparison of Generations and Climate Change Perceptions

\begin{tabular}{lllllll}
\hline Survey item & $\begin{array}{l}\text { Silent } \\
(N=22)\end{array}$ & $\begin{array}{l}\text { Boomers } \\
(N=64)\end{array}$ & $\begin{array}{l}\text { Gen X } \\
(N=75)\end{array}$ & $\begin{array}{l}\text { Gen Y } \\
(N=96)\end{array}$ & $F$-value & $p$-value \\
\hline Climate change affecting destinations & 3.24 & 3.91 & 3.60 & 3.28 & 4.181 & $0.007^{*}$ \\
Satisfied with climate conditions at destinations & 3.36 & 3.23 & 3.59 & 3.53 & 1.185 & 0.316 \\
\hline Individual climate conditions & & & & & & \\
$\quad$ Maximum outside temperature & 3.43 & 3.88 & 3.78 & 3.57 & 0.740 & 0.530 \\
Water temperature & 3.09 & 4.03 & 3.67 & 3.54 & 4.314 & $0.005^{*}$ \\
Duration of sunshine & 3.05 & 3.27 & 3.54 & 3.66 & 2.882 & $0.036^{* *}$ \\
Number of rainy days & 3.26 & 3.92 & 3.95 & 3.82 & 2.751 & $0.043^{* *}$ \\
Consistency of outside temperature & 3.17 & 3.89 & 3.71 & 3.60 & 2.468 & 0.063 \\
Amount of daily precipitation & 3.39 & 4.05 & 3.46 & 3.41 & 5.171 & $0.002^{*}$ \\
Humidity & 3.35 & 3.80 & 3.51 & 3.42 & 1.917 & 0.127 \\
Cloudiness & 3.17 & 3.59 & 3.59 & 3.33 & 1.506 & 0.213 \\
Wind conditions & 3.22 & 3.44 & 3.29 & 3.06 & 1.744 & 0.159 \\
UV radiation & 2.86 & 3.28 & 3.23 & 3.14 & 0.979 & 0.403 \\
Air quality & 3.00 & 3.19 & 3.24 & 3.36 & 0.769 & 0.512 \\
\hline${ }^{*}: p<01 ; *$ \\
\hline
\end{tabular}

Notes. ${ }^{*}: p<0.01 ;{ }^{* *}: p<0.05$. 


\section{Discussion and Conclusions}

The lack of any climate attributes' significance in affecting the opinion if climate change is affecting travel destinations may indicate several things. This may refute the commonly held belief that individuals are choosing one destination over another based on climate attributes. This is similar to Gossling and Hall's (2006) assertion that while important there is a lack of evidence weather plays a role in where a traveler may book a holiday.

Perhaps the tourists in this sample have a lack of knowledge about the historical climate of the area and therefore have no prior knowledge to base it on. This is supported in the finding that a travel agent and own past experience were more likely to be the sources of information about travel than internet sources (and presumably a more up-to-date resource). Further study examining first and repeat visitors might yield different results as repeat visitors presumably would have some additional prior awareness and avoid unfavorable times of year to travel to specific destinations. Expanding the time of year under examination beyond the time period of mid June to mid July here might yield additional insights. Alternatively, residents of the destination might also have a different viewpoint. In addition, in future research, it might be interesting to ask if the travelers believe that climate change exists and consider any effects this philosophical belief may have on travel decisions.

Weather and climate did play a role in determining satisfaction of the participants in this study. The recorded daily temperatures were higher than the averages in the travel areas of Italy, Greece, Turkey, and France and higher as found as optimal in past research (Hein et al., 2009; Lise \& Tol, 2002; Scott et al., 2008). The sample here agreed and while although preferred the warmer water temperatures desired some rainy days as a break from the higher outside temperatures.

In addition, differences among individuals from different countries on their perceptions of climate conditions and any effects on travel decisions could also yield useful information as a majority of the sample were either European or from the United States. This may be the result of those surveyed for this study who were English-speaking participants and must be considered as a weakness of the study.

In addition, this study did not consider the types of leisure activities the participants either wanted to or did engage in during the course of their travels. Therefore, the kinds of activities could be examined as a further investigation as many activities are considered as weather and/or climate sensitive.

The results presented here could suggest that age plays a role in preferred climate conditions. In general, the Silent Generation rated most of the climate attributes as less important considerations in their travels than other generations. Perhaps this generation does not travel as often or prefer more activities that are located indoors; therefore, climate conditions were not as important. Also possibly, the older generations are more flexible in the times of the year they travel as they may be retired. Namely, the Baby Boomers generation felt that the climate attributes were more important than other generations. In addition to retirement, these individuals may have a fixed income and wish to "make the most of it" while on holidays with good experience and weather.

\section{References}

Amelung, B., \& Viner, D. (2006). The sustainability of tourism in the Mediterranean: Exploring the future with the tourism comfort index. Journal of Sustainable Tourism, 14(4), 349-366.

Amelung, B., Nicholls, S., \& Viner, D. (2007). Implications of global climate change for tourism flows and seasonality. Journal of Travel Research, 45(3), 285-296. 
Bigano, A., Hamilton, J. M., \& Tol, R. S. J. (2006). The impact of climate on holiday destination choice. Climatic Change, 76(3-4), 389-406.

Braun, O. L., Lohmann, M., Maksimovic, O., Meyer, M., Merkovic, A., Messerschmidt, E., Riedel, A., \& Turner, M. (1999). Potential impact of climate change effects on preferences for tourism destinations. A psychological pilot study. Climate Research, 11, 247-254.

Carter, T. R. (1991). The hatch index of climatic favourability. Helsinki: Finnish Meteorological Institute.

Curtis, S., Arrigo, J., Long, P., \& Covington, R. (2008). Climate, weather, and tourism: Bridging science and practice. Greenville, N.C.: Centre for Sustainable Tourism, East Carolina University.

De Freitas, C. R. (1990). Recreation climate assessment. International Journal of Climatology, 10(1), 89-103.

Dubois, G., \& Ceron, J. (2006). Tourism and climate change: Proposals for a research agenda. Journal of Sustainable Tourism, 14(4), 399-415.

Eurobarometer. (2009). Europeans' attitudes towards climate change. Special Eurobarometer 313, Wave 71.1, TNS Opinion and Social.

Fishman, A. (2011). Generational targeted marketing. Retrieved from http://www.annfishman.com/

Frenkel, M. (2008). In Florida, it's the older generations, stupid. Retrieved from http://www.prweb.com/releases/floridaprimiary/voterturnout/prweb658154.htm

Gossling, S. (2002). Global environmental consequences of tourism. Global Environmental Change, 12(4), 283-302.

Gossling, S., \& Hall, M. (2006). Uncertainties in predicting tourist flows under scenarios of climate change. Climatic Change, 79(3), 163-173.

Hamilton, J. M., \& Lau, M. A. (2004). The role of climate information in tourist destination choice decision making. Working Paper FNU-56, Centre for Marine and Climate Research, Hamburg University, Hamburg, Germany.

Hein, L., Metzger, M. J., \& Moreno, A. (2009). Potential impacts of climate change on tourism: A case study for Spain. Current Opinion in Environmental Sustainability, 1(2), 170-178.

Lise, W., \& Tol, R. S. J. (2002). Impact of climate on tourist demand. Climatic Change, 55(4), 429-449.

Lohmann, M., \& Kaim, E. (1999). Weather and holiday destination preferences: Image attitude and experience. Tourist Review, 54(2), 54-64.

Maddison, D. J. (2001). In search of warmer climates? The impact of climate change on flows of British tourists. Climatic Change, 49(1/2), 193-208.

Matzarakis, A., \& De Freitas, C. R. (2001). Proceedings of the First International Workshop on Climate, Tourism, and Recreation-International Society of Biometeorology. Commission on Climate Tourism and Recreation, Halkidiki, Greece.

McMillan, M., Hoban, T. J., Clifford, W. B., \& Brant, M. R. (1997). Social and demographic influences on environmental attitudes. Southern Rural Sociology, 13(1), 89-107.

Mieczkowski, Z. (1985). The tourism climate index: A method of evaluating world climates for tourism. Canadian Geographer, 29(3), 220-233.

Moreno, A., \& Becken, S. (2009). A climate change vulnerability assessment methodology for coastal tourism. Journal of Sustainable Tourism, 17(4), 473-488.

Morgan, R., Gatell, E., Junyent, R., Micallef, A., Özhan, E., \& Williams, A. (2000). An improved user-based beach climate index. Journal of Coastal Conservation, 6(1), 41-50.

Nickerson, N. P., Becerra, L., \& Zumstein, P. (2011). Climate change \& tourism literature review. Research Report 2011-1. Institute for Tourism and Recreation Research, University of Montana Missoula.

Pendergast, D. (2010). Getting to know the Y Generation. In P. Benckendorff, G. Moscardo, \& D. Pendergast (Eds.), Tourism and generation $Y$ (pp. 1-15). Cambridge, M.A.: CAB International.

Perry, A. H. (1993). Climate and weather information for the package holiday-maker. Weather, 48(12), 410-414.

Perry, A. H. (2000). Impacts of climate change on tourism in the Mediterranean: Adaptive responses. FEEM Working Paper No. 35.00 .

Richards, G. (2007). New horizons II: The young independent traveler 2007. Madrid: World Youth Student \& Educational Travel Confederation.

Rosselló-Nadal, J., Riera-Font, A., \& Cárdenas, V. (2011). The impact of weather variability on British outbound flows. Climatic Change, 105(1-2), 281-292.

Scott, D., Gossling, S., \& De Freitas, C. R. (2008). Preferred climates for tourism: Case studies from Canada, New Zealand, and Sweden. Climate Research, 38(1), 61-73. 
Strasdas, W. (2010). Carbon management in tourism: A smart strategy in response to climate change. In R. Conrady, \& M. Buck (Eds.), Trends and issues in global tourism 2010 (pp. 57-70). Verlag Berlin Heidelberg: Springer.

United States Census Bureau. (2009). The 2009 statistical abstract. Retrieved from http://www.census.gov/compendia/statab/2009/2009edition.html

Vlosky, D. A., \& Vlosky, R. P. (1999). Exploring age-related environmental attitudes in the context of wood product certification. Working Paper No. 51, Louisiana Forest Products Laboratory, Louisiana State University Agricultural Center, Baton Rouge, LA.

Walton, J. K. (2005). The seaside resort: A British cultural export. History in Focus. Retrieved from http://www.history.ac.uk/ihr/Focus/Sea/articles/walton.html

WUnderground. (2014). Historical weather. Retrieved from http://www.wunderground.com/history/?MR=1

Yeoman, I. (2012). 2050-Tomorrow's tourism. Bristol, United Kingdom: Channel View Publications. 